\title{
Who Can Get a Place in the Noah's Ark of the 21st Century
}

\author{
Vitaly A. Eremenko \\ International Knowledge Bridge LLC USA \\ *Corresponding Author: vitalyanfi@yahoo.com
}

Copyright (C) 2013 Horizon Research Publishing All rights reserved.

\section{Epigraph: The object of the publication is an attempt to help people to rescue and preserve themselves}

Abstract. Our civilization judging by the many scientists, historians, philosophers, social scientists and natural scientists opinion is not the first and not the last one on Earth. The limited existence of any civilization always ends with one. This is the degradation with natural disasters and with the tragic fate of dying people. A character of the dynamics of their development, that is, a rise then reaching of a maximum level and a mandatory recession very resembles a normal Gaussian distribution. Dynamics of human survival is also a kind of a Gaussian curve, but it is significantly different from the curve of the dynamics of a civilization with the time parameters. Index of the human' survival rate begins to fall rapidly while the rate of civilization' development is still held at maximum. The main reasons for the downfall of civilizations have always been conflicts between the laws of nature and society, when they reach the extreme limit. Reasons for the decline of the survival rate in growing of the number and capacity of external and internal dangers to human health and life. Natural disasters, technogenic catastrophes, terrorist and military actions rations belong to the external dangers; however a rapidly growing of bureaucracy is a basis for increasing of internal ones. The biological instinct of self-preservation is the primary and often the only guarantee of survival in the initial and final stages of the development of civilizations. However, the transition to an application this basic instinct should start now with due regard the above-mentioned shift in the dynamics of these two Gaussian curves, characterize the dynamics of the survival rate and the civilization' development . So that is must be done before the "Great Flood" will come. Issues develop an adequate Paradigm for survival of an ordinary man and Methodologies, Technologies and Design of a special cybernetic device that is the Cybernated Self-Preservation' Kit for personal use is the subject of this publication.

Keywords Civilization, Ordinary Real Person, Dangers, Phobias, Risks, Survival, Cybernated Self- Preservation

\section{Prologue}

Even though crisis, catastrophes and accidents arose and previously in the way of development of different civilizations, the modern historical period justifiably is qualified by the majority of scientists as a period of such profound crisis which makes its unmatched in a scale the entire preceding history of humanity. Furthermore the civilization's crisis the 21 st century threatens not only further existence of human society, but to the himself man as a biological species. Figure1. [1]

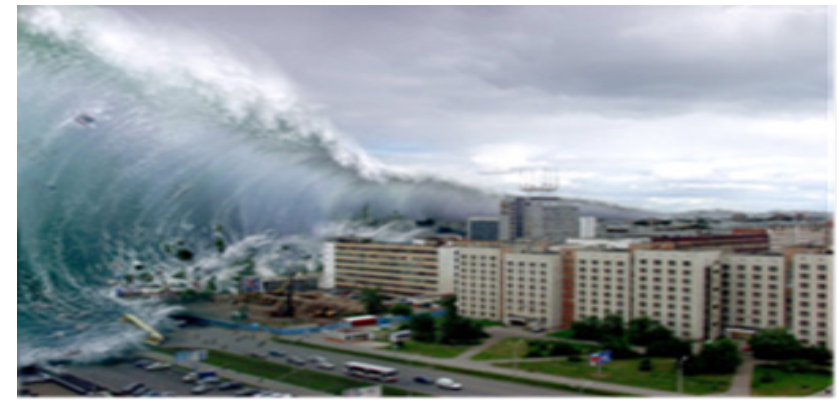

Figure 1. The civilization's crisis the 21 st century threatens the continued existence of the whole mankind.

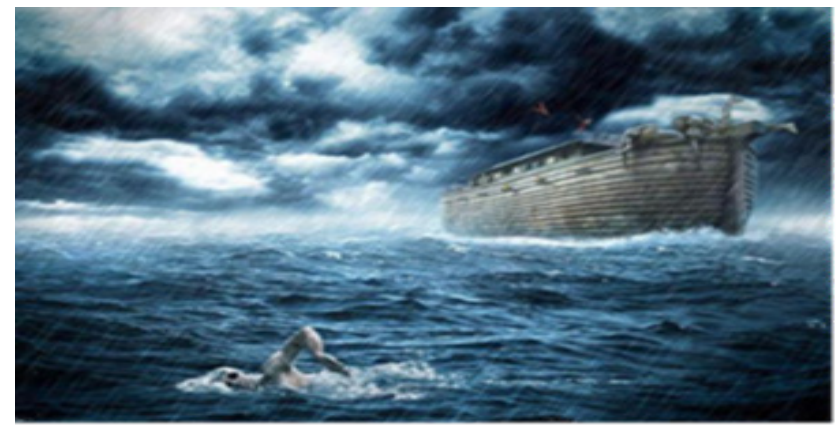

Figure 2. NOAH'S ARK in the Bible / Qur'an means a refuge for rescue the favorites of individuals and animals from the Deluge

NOAH'S ARK, according to the Bible / Qur'an - a refuge that was built by the righteous man Noah/ Nux to rescue the human race and animals from Great Flood: "And God / Allah said to Noah /Nux: "Now the end of all flesh has come before $\mathrm{Me}$, because the Earth is filled with violence through them. I will destroy them. Make yourself an Ark . And by the Great 
Flood was covered the entire surface of the Earth. Over the waters was only the Ark, built by them. And every living creature except those that were in the Ark, lost their lives"(Genesis6:3-16; Sura11:37, 54:14).Figure 2.[2]

Trio lucky guys that will undoubtedly get admission into the Noah's Ark the 21st century are shown on the Figure 3. All these guys are fitted out and know how to use "kits of cybernetical devices" whose sizes are close to cell-phones' sizes. These devices are referred below as "Cybernated Self-Preservation Kit's". One of these guys is in the center of the Figure. His "Noah's Ark" is home or office. Another who is at the top right is walking. His "Noah's Ark" at the moment is with him. At last the one who at the top left is driving the car. His "Noah's Ark" - his own "vehicle" and can be his plane, boat, etc. Figure 3. [3]

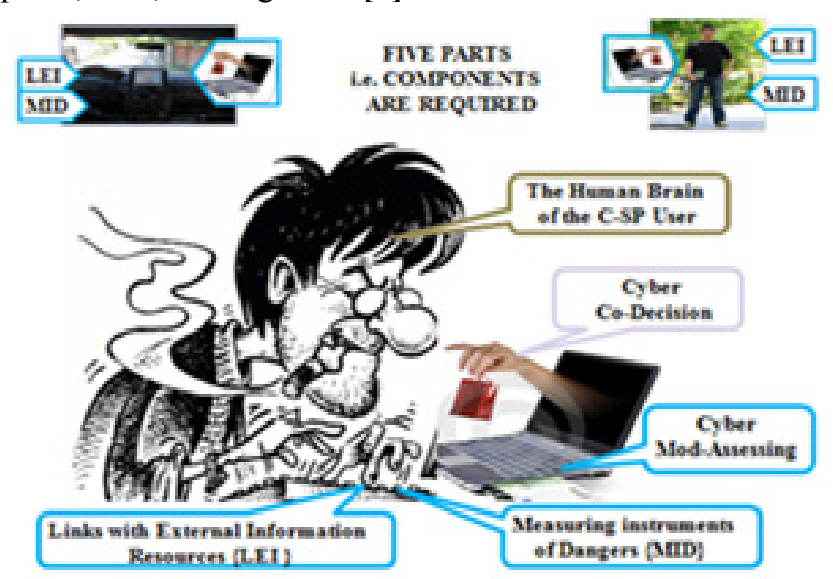

Figure 3. Three Guys will be admitted into the Noah's Ark the 21st century as they have and use kits of "Cybernated Self-Preservation".

\section{Introduction}

\subsection{One of the Primary and Vitally Important Problems of Our Time is the Survival of a Real Rather than a Hypothetical Man.}

As known, survival of the human being, and of the rest of the biota, is provided by biological self-preservation that is the main fundamental instinct for the preservation and continuation of life.

In spite of this such remarkable natural ability of man is almost lost during the consumer civilization and especially for the last period of postindustrial development At the same time, the number, frequency and specificity of deathly dangers and threats of the post-industrial environment (the noosphere) have risen sharply for humans in general, but above all for every separate real individual. Precisely a ordinary man who is living in a separate house or uses his/ her own transport especially during the offensive of dangers such as large scale industrial nuclear accident, explosions and fires on transcontinental oil / gas pipelines, natural disasters, terrorist or military actions.

This individual is most susceptible to danger's negative impact since the start of the offensive of dangers and in further for an uncertain periods of time. As a rule he/ she remains practically unprotected and beyond the reach from the special government services and administrative systems of safety in emergency situations. The attempts to solve the problem of survival of the individual through the improvement of the traditional paradigm Hygiene and Sanitation of Medicine, comparatively recently amended by Administrative Response to Emergency Situations were in vain.

But more than that, a dramatic increase of bureaucratism in the management of the centuries-old and well-established paradigm of Hygiene and Sanitation, and especially in its modern appendage in the form of the Administrative Response to Emergency Situations (here and after AR-ES) the one hand, as well as an irresistible inertia in deploying their emergency forces and resources the other hand, causing not only the growing critical attitude to their effectiveness, but even allow to consider and rank these existing paradigms as infected by bureaucracy and belonging to the number of even threatening to the human survival today.

In 1992, the United Nations organized a conference on environment and development in Rio de Janeiro, called the Earth Summit. The purpose of the conference was to rethink economic growth, advance social equity and ensure environmental protection. Twenty years later, the UN is organizing Rio+20, a chance to move away from business-as-usual and to end poverty, address environmental destruction and build a bridge to the future. Disaster risk reduction (DRR) plays an important part in this future of sustainable development. As the result we can look at the impact of disasters since 2000 up till 2011 in Figure 4.

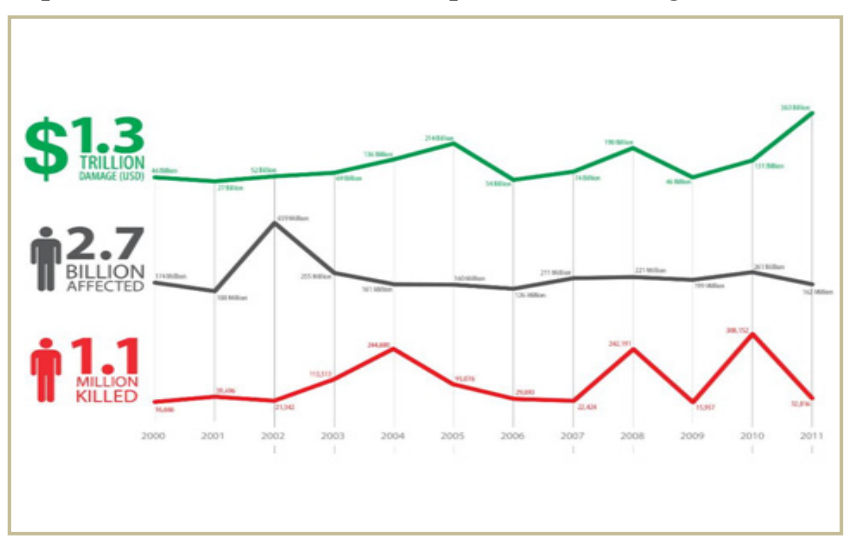

Figure 4. Disaster impacts of 2000-2011 by UNISDR.

The UNISDR registers three types of consequences, it's the financial loss, the number of people that were affected and killed by the disasters (green, black and red curves respectively).[4]

\subsection{Three Major Obstacles in Solving Problems of Survival of an Individual 21st Century: the Bureaucracy, the Lack of Information and Phobias}

An average man with his / her individual needs remains aside of their attention and services. It's particularly evident 
while large-scale catastrophes or natural disasters covering large populated spaces. Not a factual but a hypothetical person still featured in the modern politics, strategies, and systems of population safety.

Such failures of the administrative emergency response in protection of an average man systematically occurs , and will occur in the future, because the deployment of existing federal centers of emergency situations takes tens hours from receipt of alarming information and prior to providing assistance to potential victims. The similar also occurs with the municipal centers of emergency which deployment takes hours and tens of minutes in the best case. Such time is "quite enough", for example, $100 \%$ of people who would find themselves at risky zone, can die of the "persistent and unstable high-speed" toxicants (aniline, furfural, hydrogen cyanide, ammonia, carbon monoxide). Such time of delay is "enough" for the same percentage of people, who can get severe hemodynamic shocks from radiation exposure: lethal outcome occurs in the first 3 days, sometimes - in the first hours. The same the plight of expects till $40 \%$ of helpless people who die via 1 hour in the risk zone of destruction buildings and fires provoked by the industrial catastrophes. Close to these data are reflected in the statistics of victims of first minutes, hours - days from the start of destructive actions of the tsunami, hurricanes, large scale fires and explosions, terrorist or military actions. [5]

A negative impact of contemporary priorities of the economic bureaucracy and their consequences in the form of ineffective emergency response are permanently hindering the fulfillment of necessary conditions of man survival and especially for man living in the urban environment. It is very alarming situation which requires adequate decisions on a updating or even full replacement of the concept and technology of emergency response today and now, because the frequency and severity of emergency situations in the world is steadily increasing.

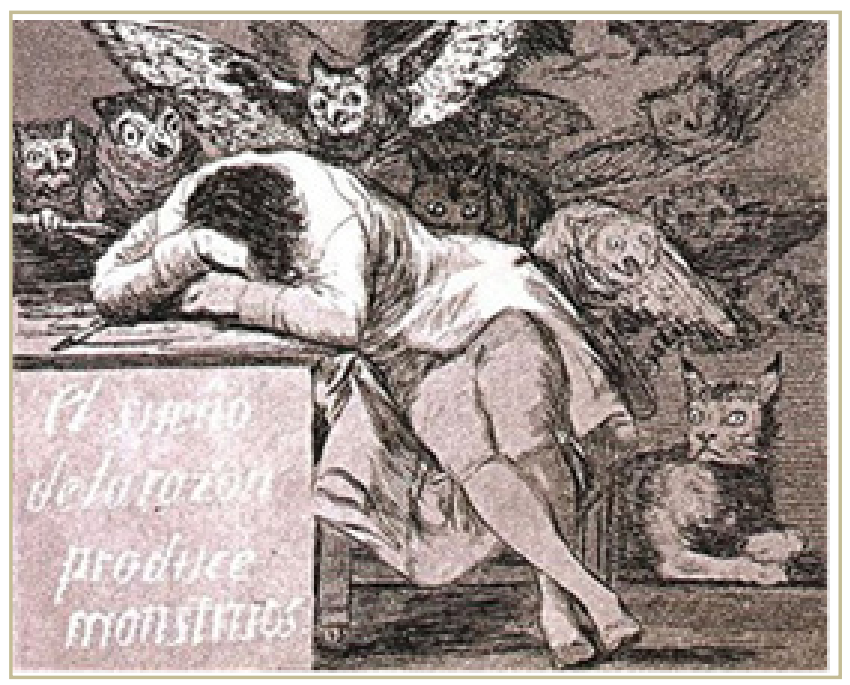

Figure 5. Francisco Goya "Sleep of Reason Produces Monsters"

In its turn, the number of illnesses and deaths is clearly correlated with the levels of stresses phobias amongst the people who have lived in those territories and have been subjected to emergency's dangers for the previous months and years. The post-industrial dangers may be the cause of Radiophobia (fear of radioactivity), Agoraphobia ( fear of places or events where escape is impossible or when help is unavailable, fear of leaving a safe place), Aquaphobia ( fear of water), Pyrophobia ( fear of fire ), Chemophobia (fear of chemicals), Seismophobia (fear of earthquakes), etc. [6]

As to the severity of phobias consequences, so they are a direct result of the no effective management by emergency response which is carried out the centralized bureaucratic systems based on mostly economical priorities. As a result the numbers of appearance, prevalence and severity of consequences of post-industrial phobias are determined by the degree and quality of performance, at least by two of the above conditions of human survival. This refers to the early warning and detailed awareness of each average man about data the impending dangers.

For example, it may be argued in advance that no small role in appearance the various phobias and elicited by them diseases and deaths would play the over four thousand natural and technological disasters the last decade the current century. These man-made and natural disasters have jeopardized of survival of approx.2.7 billion people the last decade, with $74 \%$ of them in Asia. Among these should mention one of the most devastating earthquake and tsunami and then the nuclear accident at the Fukushima NPP with the direct loss of more than 15,000 people in Japan ( radiophobia and agoraphobia have not yet manifested as their victims have to emerge in the subsequent 2-4 years). It's also the recent earthquake in Turkey with the immediate deaths of more 600 people( seismophobia have not yet manifested itself as a small time) and the flood in Thailand with submersion 26 of 76 provinces accompanied by the direct loss of more than 500 people (aquaphobia and agoraphobia have not yet manifested itself the same reason as the above events). At last the floods, droughts, hurricanes, tornadoes and fires in the U.S. claimed the more than of 500 lives. [6,7]

The above data once again confirm the existence of a deterministic links between survival and of awareness: people surviving greater there where these people could be informed about the danger's specific in a greater extent and in more detail. The very existence of the AR-ES and its information networks in Western countries provides huge advantage in the numbers of survived people in comparison with Asian countries in spite of the very similar emergencies. Meanwhile, these data are testify only that the existence of AR-ES is preferable his absence. A number of facts given earlier give every reason to believe that the AR-ES which focused on safety protection of the public as a whole and also poisoned by bureaucratism is absolutely not effective in securing and survival of any individual.

Moreover, politicians and bureaucrats, who are represented by the authorities and administrations at various levels, is always "turning their faces" not to safety of his subjects but unsuccessfully trying to suppress the sources of danger.. 


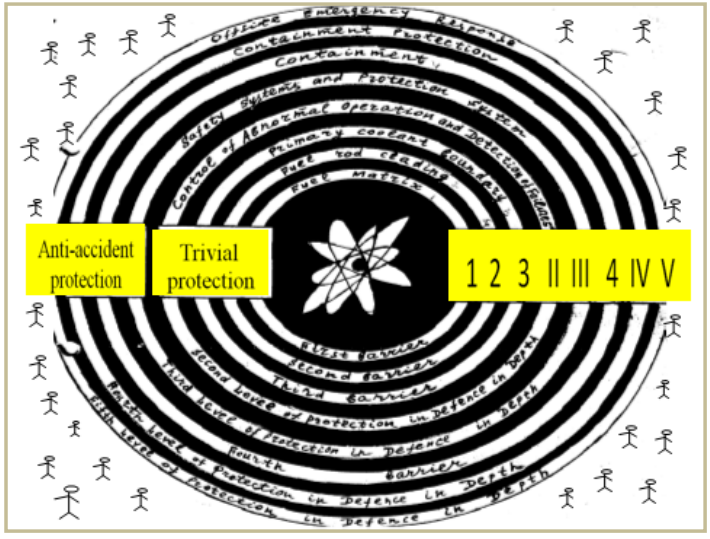

Figure 6. Illustration of the conservative safety philosophy of the 80ths $20^{\text {th }}$ century (the conception of IAEA)

These were shown as a particularly clear, for example, in the process of liquidation of severe nuclear accidents at Chernobyl (1986) and Fukushima (2011). Bureaucracy Japan in 2011 and the Soviet Union in 1986 were demonstrated a surprising unity in choosing priorities and decisions made for during disasters more for "safety of their prestige" than for population safety. This is because they are by nature a concept close to the IAEA "Levels and Physical Barriers for Protection and Defense in Depth". This approach was accredited in times when the priority a facility safety against the population safety transformed in the relevant technologies.

The components of the physical barriers and defense levels by IAEA are grouped into two sub-groups. The first sub-group named as "Levels of Protection" and their components are: I. Conservative Design; Quality assurance; Surveillance; Safety Culture (ASCOT). II. Control of Abnormal Operation and Detection of Failures. III. Safety Systems and Protection System. IV. Containment Protection. V. Offsite Emergency Response.

The second sub-group named as "Physical Barriers" and their components are: 1. Fuel matrix. 2. Fuel rod cladding. 3. Primary coolant boundary. 4. Containment.

This safety design philosophy for dangerous facilities was set at the eighties of the last century and illustrated by Figure 6. This safety philosophy for dangerous facilities is fully consistent with the risk methodology the FCRA' type which is used for centralized systems of safety and with the paradigm the Administrative Response to Emergency Situations (AR-ES) used till now by most modern authorities. Surprising coincidence inhumane policies of emergency response governments of the USSR in 1986 and in Japan 25 years later, who are ideological antipodes, indicative of identity, harmfulness and the constancy in time of the safety criteria for any bureaucracy $[6,7,9]$

\subsection{The First Alternative Traditional Philosophy with Promoted to the Same Level of Priority}

One way or another the protective physical barriers alternating with levels of the safety management developed by the IAEA was successfully tested in the future for the safety of nuclear facilities. Exactly they were selected by us as a good tested prototype for wording of the list of protective physical barriers and levels of the safety management oriented on a person's preservation. They are shown Figure 7. [8]

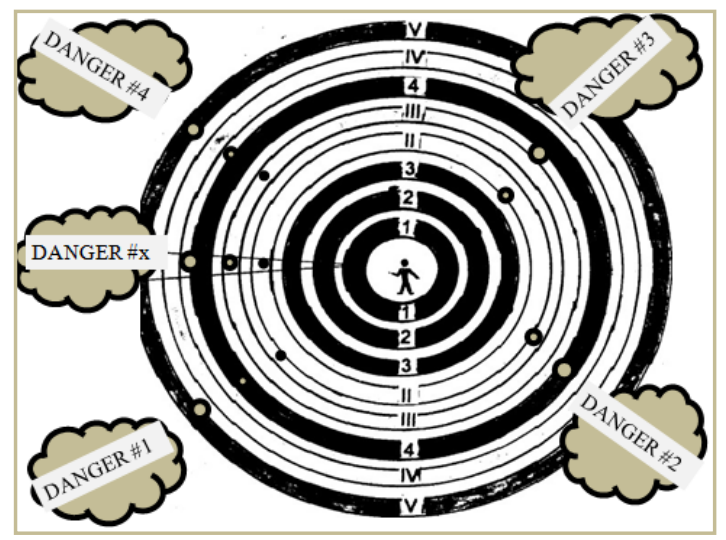

Figure 7. Illustration of the philosophy of the real ordinary man's preservation in the 21th century (the paradigm and conception of self-preservation)

The image above is outwardly similar to the IAEA "physical barriers and levels of protection in defense in depth" which were destined for minimization of dangerous for population of emissions which are went outside of the boundaries of given facility. This approach was used and revised as an alternate approach for maximize of the protection of the common man against the danger when this danger has moved beyond the boundaries of an industrial facility or of the epicenter of a natural disaster or the terrorist or military action.. Here the "Levels and Physical Barriers for Protection and Defense in Depth" include:

Physical Barriers: 1. Person organism immunity. 2. Adequate guise and favorable surrounding of individual (clothing, diet, healthy environment). 3. Favorable outside surroundings (house, office, air, water, transport). 4. Favorable region surroundings (accessibility of food products, pure water and medicine, availability of collective protection systems, and having of the nearest police and fire departments).

Levels of Individual Protection in Defense in Depth:

II."In situ " person making decision for self-preservation and rescue of a family and the personal property (basis for the decision-making can be, either indicating of measuring instruments or/and computer advisors). III. "Ex situ"- local authority infrastructure of observation for immediate local people information on a coming true or potential menaces / danger/ hazards everywhere in this local community and adjoining areas (it may be proposed to the local police and fire departments which would provide every needy individual with advices and recommendations on self-preservation; the measuring instruments and computer advisors would be sources for elaborating advices and recommendations on self-preservation of local individuals). IV. Regional governmental infrastructure of observation for immediate public information on a coming true or potential 
menaces / danger/ hazards everywhere in a given area and in the adjoining ones. V. Federal and municipal administrations infrastructure of observation for immediate public information on a coming true or potential menaces / danger/ hazards everywhere in this country and adjoining countries.

\subsection{The Second Alternative to the Traditional Philosophy of Safety with the Priority Attention to Sources of Dangers It is when the Traditional Approach is Replaced with the Paradigm and Technology of the Human Self- Preservation}

The traditional philosophy of industrial safety was designed for minimization of negative impacts consequences of industrial accidents on the population health. The idea was to block a danger and absorb its within the facility and didn't let the danger to cross boundaries of the facility that was a source of these dangers. Indeed, the IAEA approach was destined to minimize the danger of discharging radioactive emissions with impact them on the nearby population. It has to emphasize that term of "population" has kept in mind in this methodology not groups of real individuals where each has his / her peculiarity but they are hypothetical persons, i.e., an abstract items united by this conditional name for participating in the formal analysis.

The presented here an alternate approach is destined to maximize the protection, safety and survival of a real common man, instead of the faceless "population".

This alternative approach i.e. of its paradigm, methodology and technology of the Cybernated Self-Preservation was designed to protect of the any real individual against of modern dangers.

The Cybernated Self-Preservation' Kits start their work when the any dangers begin their moving beyond the boundaries of a potential hazardous industrial facility either a danger is moving beyond the epicenter of a natural disaster or of a terrorist or military action.

\subsubsection{Definitions}

Cybernated Self-Preservation' Kit is a human-computer symbiosis for maximization of survival ordinary man midst dangers the contemporary post-industrial world $[10,11]$.

Semantics of the name "Cybernated Self-Preservation" based on a combination of two different concepts - the biological self-preservation [12,13], and technical information - "cybernated": "Cybernated control a function or process"[14]; "Cybernetics is the interdisciplinary study of the structure of regulatory systems. It is equally applicable to physical and social (that is, language-based) systems. Concepts studied by cybernetics include, but are not limited to: learning, cognition, adaption, social control, emergence, communication and efficiency and interconnectivity"[15].

This combination of heterogeneous terms was chosen for the C-SP title for two reasons. The first reason incommensurability of indicators - receptors of the fundamental biological instinct with parameters of dangers and threats for the modern industrial environment (the noosphere): "Man - a biological creature, all his/her senses were formed during the long evolution, so that their sensory range would be sufficient for human adaptation to life under initial terrestrial conditions. However, the range of the receptor is very limited in comparison with the variety of modern information signals. It has always been a hindrance in the objective - full view of the Man about the world, and now in post-industrial world it has become a threat to Man survival"[16].

There is another reason for combining of biological self-preservation and cybernetics. Cybernetization of biological survival instinct allows activating the "chaste" biological self-preservation, and significantly amending and strengthening the community of paternalistic paradigms AR-ES and HS-M at the difficult period for them.

\subsubsection{Is There a Really Need in the Cybernated the Inborn Biological Instinct of Self-Preservation}

Yes, as man is almost lost this remarkable natural ability for the last period of industrial development. At the same time, the amount and specificity of the death threats and risks increased sharply. The reason for the involution of this innate ability to self-preservation of man can be explained by three factors [6].

The first is mismatch in ranges of human biological receptors with physical indices of modern industrial and natural dangers and phenomena. The second is the fading of this inherent ability as a result of its lengthy substitution through man-made paternalistic security systems. And third, as a consequence of the first two, the powerlessness of the self-preservation to perform an autonomous and independent assessment and identification of hazards and risks of modern industrial environment (the noosphere).

Nevertheless, still it would be a mistake to allocate self-preservation a secondary role in ensuring the survival of man today. Complement of this fundamental biological instinct using modern information technologies can be the unique solution of the conceptual problems of human survival at the present time. The upgraded paradigm of survival while it supplemented by the cybernated selfpreservation can minimize the threat to the health and lives of each and every individual in emergency situations of modern post-industrial era.

The aim of such modernization is to ensure the human survival with a minimal depending from the existing paternalistic federal and municipal bureaucratic centers of the AR- ES. High efficiency for the upgraded paradigm is achieved by availability of cybernated means, their autonomy and personification. The demand, implementation and use of this paradigm would open a way for elimination of the existing imbalance between threats of current industrial development and primary vital interests of the each and every man -his / her "health and life".

2.4.3. The Fate of Modern Civilization Does Not Depend on the Individual Human; the Fate of a Single Human is 
Totally Dependent on His Knowledge And Skill to Properly Use the Information

The limited existence of any civilization always ends with the degradation which culminates in turn with natural disasters and tragic fate of dying people .The biological instinct of self-preservation is the primary and often the only guarantee of survival in the initial and final stages of the development of civilizations.

However, the transition to an application this basic instinct should start now with due regard the above-mentioned shift in the dynamics of these two Gaussian 'type of curves; characterize the dynamics of the survival rate and the civilization' development.

Inevitability in returning to the initial ancient Biological Self-Preservation, if it would be modernized with due regard to the advances of information and cybernetic technologies caused by extreme vulnerability of human life from the dangers and threats of the modern post-industrial world. In this paper classification of the theory, design, development and implementation of this innovation is made with an application to a specific implementation and use of the Cybernated Self-Preservation Kit the practice of making decisions on rescue and survival of each and every person and his / her family in an ever-increasing threats and risks of post-industrial world.

As a starting point are posed and solved, for beginning, at least four applied tasks on rescue and survival of each and every man with respect to any industrial accident caused by human errors, natural disasters or terrorist actions. They are providing the possibility the contentiousness of mind and cybernetic devices in making decisions while designing of the Cybernated Self-Preservation Kit, firstly.

Then a sense of the self-confidence in the ability of man who uses the Cybernated Self-Preservation Kit to withstand any hazards and life-threatening phobias to ensure the survival of any individual in the first three days of the start of distress as minimum, secondly. This is because the existing bureaucratic systems and service unable to help the individual person with real rescue actions.

Third task is to provide of each individual a clear program of action in case of evacuation in the fourth and subsequent days of an emergency to ensure the readiness of each individual to survive and continue live in a time of global catastrophe through transforming his / her of house in the long-term refuge in this case of global dangers.

It's very important in any scenario of emergency contingency plan of actions has to be considered the minimization of any phobia. That is the most important distinctive quality of the Cybernated Self-Preservation Kit and the stimulus for its mandatory use. The main problem are the phobias, which are the main cause of most serious illnesses and deaths of people located in risk zones of severe industrial accidents, natural disasters and terrorist acts.

There is a vitally important problem that is still not resolved. This is ensuring the survival of contemporary ordinary person who gets into the impact zone of any large-scale technological disaster or any natural disaster including those caused by terrorist or military actions.

As mentioned above the deployment of existing federal and municipal centers of emergency situations takes correspondingly dozens of hours and tens of minutes from receipt of alarming information and prior to providing assistance to victims. The instinct of self-preservation inherent in every person also does not solve the problem at least for the above-mentioned period of time, due to the unsuitability of the biological human receptor to recognize and identify the contemporary dangers.

Implementation of the Cybernated Self-Preservation' Kits could solve the majority of above listed problems. The Cybernated Self-Preservation composition fills the existing gap nowadays between modes and means which would have been able to ensure the survival of the ordinary man in the modern post-industrial world. On the one side of the gap lays the unsuitability and inadaptability of the innate biological ability of man to make the right decision for survival because human receptors cannot detect and identify the threats of modern post-industrial world.

The administrative governmental systems of emergency response existing in every country and designed seemed to exactly for this goal also cannot fill up the gap. Firstly, they are targeted for providing safety of large groups of hypothetical persons named as "population". [5,6,8]. An ordinary real person stays outside the focus of these ambitious, expensive and therefore bureaucratized of systems the centralized management. Secondly, these systems unwieldy and, as a result, they all incurably sick with a chronic delayed when deploying.

Implementation and use of the Cybernated Self-Preservation can secure the survival of each ordinary person and his / her family for first minutes, hours, days from the beginning of damaging actions and from deadly dangers caused by the large scale catastrophes and terrorist or military actions, when and where an ordinary man is most susceptible to the dangers negative impact.

Owning and use of the Cybernated Self-Preservation's technology guarantees the survival of the ordinary individual in the most severe emergencies, even if, for whatever reason, the forces and resources of the AR-ES will not be able to help an ordinary man and his / her family on the fourth, fifth and subsequent days .[10,11]

\section{Paradigms of Safety and Survival}

So, post-industrial civilization in the 21 st century is indeed entered the final phase of its existence. All living today individuals must be prepared for meeting and be protected from any of severe threat within the local, regional and even global catastrophes every day .Unfortunately, the history of past civilizations practically haven't left us of recommendations on how we could be protected from the negative changes and the emerging threats and dangerous trends of the current time.

Meanwhile, dangers that threaten a person are changing 
with the time also. As a consequence, theory and methods of their study, models conversion to risk of hazards for life and health, so called paradigms of survival, the mainstreams over a certain period of history in the scientific and social community are being modified too. Listing of the historical linkages of threats to human health and life with the corresponding survival paradigms allows tracing and to reveal a natural tendency their cyclic recurrence. [6, 11].It can help us to find a way for protection of an individual from the current dangers, i.e. to find a place in the Noah's Ark of the 21 st century.

\subsection{Period under Review is from the Earliest Times up to about 8 to 4 Thousand years BC.}

Dangers: micro-and macro-organisms of the biosphere and the natural disaster's consequences, that is All that threatening a man from the outside and inside.

The paradigm of survival: Hygiene and Sanitation of Medicine (hereafter MHS-M).Survival of the human as however and the rest of the biota are provided by one of the principal fundamental instinct, that is the self-preservation [17]. Furthermore, this unique ability of the organism to survive without any artificial external assistance is called Biological Self-preservation (hereafter - B-SP).

\subsection{Period under Review is after 8 - 4 Thousand $B C$ and until the Middle of the XIV-XV Century}

Dangers, which caused the greatest loss Homo sapiens that time and therefore, was selected as a priority: micro-and macro-organisms of the biosphere and the consequences of natural disasters.

Additional dangers: high population density in the nascent cities. This is why the paradigm of survival is the modified MHS-M. Its domination has been completed after these dates when Europe was hit by "tsunami" of epidemics that carried away millions of lives. The limited capacity of HS-M proved to be inadequate to response to a new source of hazard. It was the danger of unprecedented earlier density of population into newly the nascent European cities.

\subsection{Period under Review is between the Middle of the XIV -XV Centuries and up till the XVIII Century}

New hazard: high population density in the nascent cities. Additional dangers: pollution of the biosphere, industrial accidents, population growth in general and the cities in particular.

The paradigm of survival: the modified Hygiene and Sanitation of Medicine (MHS-M), amended by the Administrative Response to Emergency Situations (AR-ES). The knowledge and technology from the natural and social sciences and their practices were accepted by the hygiene and medicine, as well as by their sanitary and epidemiological applications.

Meanwhile the new list of mortal dangers to humans has been refilled with a number of new units at the same time in the second half of XX century. As a result, even an updated paradigm as the HS-M was not able by alone to ensure the priority of vital interests of the man in the industrial and postindustrial world with such a combination of hazards.

\subsection{Period under Review is after the Second Half of $X X$ Century and up till beginning XXI Century}

A few new hazards: pollution of the biosphere, industrial accidents, population growth in general and the cities in particular. Additional dangers: paternalism and bureaucracy in responding to the emergencies.

The paradigm of survival: the HS-M, supplemented by the AR-ES. It was just a palliative solution of the HS-M problem.

Almost fifty years of experience in the use of specialized administrative centers and systems of the AR-ES showed their inability to ensure the health and life of the separate individual in the postindustrial world of XXI century. Paternalistic nature of the AR-ES and steadily increasing bureaucratism in decisions making, irresistible inertia of the response to emergency calls, as well as orientation toward protection of the "general population", i.e., population in general, rather than of every particular person are typical of the AR-ES centers and systems, regardless of country or region of their location.

The leading and understandable strategic principle of the AR- ES is to provide assistance to the most potential victims and where they are located and not to a separate one [11]. The fact is the bureaucratic governance in the HS-M as well as particularly in the AR- ES, and as a consequence the inertia in the deployment of forces and equipment, should be considering amongst main threats to life of each person in the beginning XXI century.

A concrete individual with his / her individual needs remains aside of attention and services of the AR-ES, while large-scale technogenic catastrophes or natural disasters are happening more and more often.

One more reason for claiming of a more pertinent paradigm of survival is the deployment of existing federal and municipal centers of emergency situations. It takes between tens of minutes and hours or even several days from receipt of alarming information by the HS-M and the AR- ES and prior to providing assistance to victims.

Examples of inefficiency the AR-ES paradigm are the tragic consequences for many people from the release of dioxin in the Seveso, Italy (1976), or the radioactivity from the Chernobyl (1986) and from the Fukushima Nuclear Power Plant (2011). Life or death of an individual in these cases depended on his/her accidentally geographical location relative to epicenter of an industrial hazard, from random weather conditions at the place of his / her staying [7].

As logic explanation of the reasons of abovementioned event can be stated on the priority of paternalism and bureaucracy in generating the emergencies in the beginning XXI century. Exactly the paternalism and bureaucracy in the 
emergencies are responsible for the appearance numerous life-threatening phobias. As a result life or death of an individual in the emergencies situations depends on his / her accidental geographical location to relative to the origin epicenter of a catastrophe, severe accident or a terroristic action as well as from random weather conditions at the place staying of the individual.

So, the long life cycle of the paradigms of human survival, which has begun since the ancient B-SP, and what in turn has been consistently displaced by the HS-M and further has been extended with the AR- ES, has to be logically completed by the B-SP modern analogue - Cybernated Self-Preservation $[3,5,6]$.

This is why could be say that the paradigm of survival today is the MHS-M, amended with the AR-ES and with the next amended in the form of Cybernated Self-Preservation (C-SP).

\section{Methodology of Cybernated Self-Preservation}

\subsection{Cybernated Self-Preservation's Kits as a Typical Example of the Transition to Decentralized or Distributed Systems Management for the Rescue and Survival of a Modern Individual [5]}

Methodology distributed / decentralized systems of safety management based on risk management has been developed and then discussed in detail in the early 2000s [5,]. Principles and methods of organizing and constructing a theoretical and practical activity, that is, methodology of the Cybernated Self-Preservation's Kits is one of the applied branches of the first one. $[8,11]$

The fact is the defenselessness of individuals involved onto anthropogenic accidents or natural catastrophes continues to increase despite of establishing by governments of various additional restrictions in everyday life of people and permanently enlarging budgets for supporting and developing Centralized Systems. There are many reasons for this. For example, this is a modern phenomenon of increasing amount and consequences severity of natural disasters and industrial accidents. This is also threats of expansion of risk zones at terrorists acts and as well as potential nuclear or toxic industrial accidents which can be provoked by terrorists. Modern man is beginning to understand that nuclear, chemical, biological industries and transportation of hazardous materials not possess absolute reliability and absolute anti-accident rates. All they are potential sources of death hazard.

As known the first aid must be made for exposed by radiation or toxic impact of individual immediately or not more than the next $30 \mathrm{~min}$ after her / his extraction from danger zone. There is data that without having obtained the necessary aid at such cases, $40 \%$ of the heavily struck die through $1 \mathrm{~h}$, more than $60 \%$ of men die in the next $3 \mathrm{~h}$, and at last $95 \%$ staying without aid die after 6 hours. For example, the radiation impact on an individual from an accident or a terroristic act on a Nuclear Power Plant develops for the first minutes. Thus the Irreversible consequences of radiation defeat of intestine organs reveals itself into the first 15-30 minutes following an emergency radioactive release on nuclear facilities ( e.g., NPP , test facilities, etc.).. The lethal outcome happens as a result of such exposure sometimes for the first hours.

It is understandable that inertia inherent for all Centralized Systems, the AR-ES for example, have been and would always impeded to get required aid to every person within such limited time. The problem can be solved only through the development and implementation of Decentralized / Distributed Systems for safety of any individual. Development and implementation of a Cybernated Self-Preservation's Kits is a typical example of the transition to the Decentralized / Distributed Systems management of rescue and survival of the individual human of the 21 st century.

\subsection{Selection between the Two Groups of Risk's Methodology on the Criterion them Usefulness to Rescue and Survival of the Individual in the 21st Century}

In the applied theory of safety management there are two main alternative sets of risk's methodology on the current day.

That is Probability Risk Analysis (PRA) and Human Health Risk Analysis (HRA) which practically repeating its[8, 18, 19]. In $[8,20]$ the both of these approaches have been combined under a common name of this set, that is "Facility-Centered Risk Approach" (hereafter FCRA).

In the same $[18,8]$ has been proposed and substantiated an alternate principle of risk management for the modern individual which was named "Human / or Individual-Centered Risk Approach" (hereafter ICRA).

The existing traditional systems of hierarchical centralized governmental regulation and management for population safety traditional based on the FCRA methodology. 


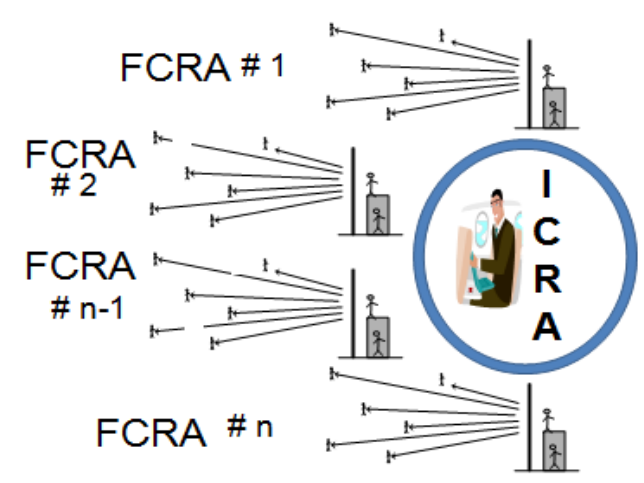

Figure 8. Aggregated risk assessment through ICRA vs FCRA assessing each source separately (multiple menaces are emerging together and simultaneously)

Here is notified about a group of alternative systems, about so called nongovernmental systems of the distributed decentralized management of safety and survival for individuals, who make their decisions regardless of the local and central administrations. Their methodology will be the ICRA [9, 20,21 ].

In really, the governmental systems of hierarchical centralized management (hereafter "Centralized Systems") with more and more increasing difficulties provide protection and safety of population in today's world. However, a lot of evidences show that neither the Centralized Systems nor the HRA or FCRA prove to be having sufficient effectiveness in the application to individuals. That is because all they are aimed for providing of safety not of a real man but for hypothetical persons united by conditional term of "population".

It is easy to show that effectiveness of the present systems designed for protection and safety of hypothetical people and based on the FCRA is evidently insufficient in application to real individuals. That is because the Centralized Systems are aimed on safety of all population mass but ignore a specificity and variety in providing protection and safety of an each concrete person. And also managers of such type of systems, the mostly are government officials, always lag in decision making. At last these systems are characterized by big inertia in the action deployment.

As a result they require the significant time for preparing and positioning before than to begin performing the actual work. Meanwhile the health and life of an individual involved onto accidents or catastrophes directly depends from time and quality of rendering actual first aid for seconds and minutes. Moreover the all "Facility-Centered" rsk methodologies, e.g., as FCRA, so the PSA, HRA and also all Centralized Systems were not designed for minimization of the impact effects on people from the multiple menaces / hazards / dangers which could been emerging together.

Only such choice can eliminate the above problems (Figure 6) This is why there is a possibility to assert this problem can be really solved but only by means of development and intruding of Decentralized Systems which can be realized by proposed below by compact systems that is the Cybernated Self-Preservation's Kits (C-SP'Kits) for the personal usage $[1,2,4]$. Thus, everyone now can act for his/ her self-preservation through using such kit.

Thus the specialized protective and safety measures for person preservation will be actualized through the individual preservation with the C-SP' Kits.

In turn, the C-SP'Kits will constitute a matrix structure of the Decentralized Systems. This is why exactly the C-SP'Kits have to be distributed among the all people.

This will help to make optimal decisions for ensuring safety of any concrete person and his/her family against of man-made disasters and accidents, the natural calamities or terrorist acts. This can provide a possibility to each individual to re-equip his / her family dwelling and their personal transport, converting them into the reliable refuges from the most of the menaces /dangers of this very complex time

However, in reality, the virtually is not easy embody such task for two reasons. Firstly, because of their complexity, as imply from the person of certain knowledge and experience to work with computer models. Secondly, because of the C-SP'Kits cost may be high, at least in the initial period for these Kits implementation. These concerns require special attention and discussed later in the Section "Discussion". 


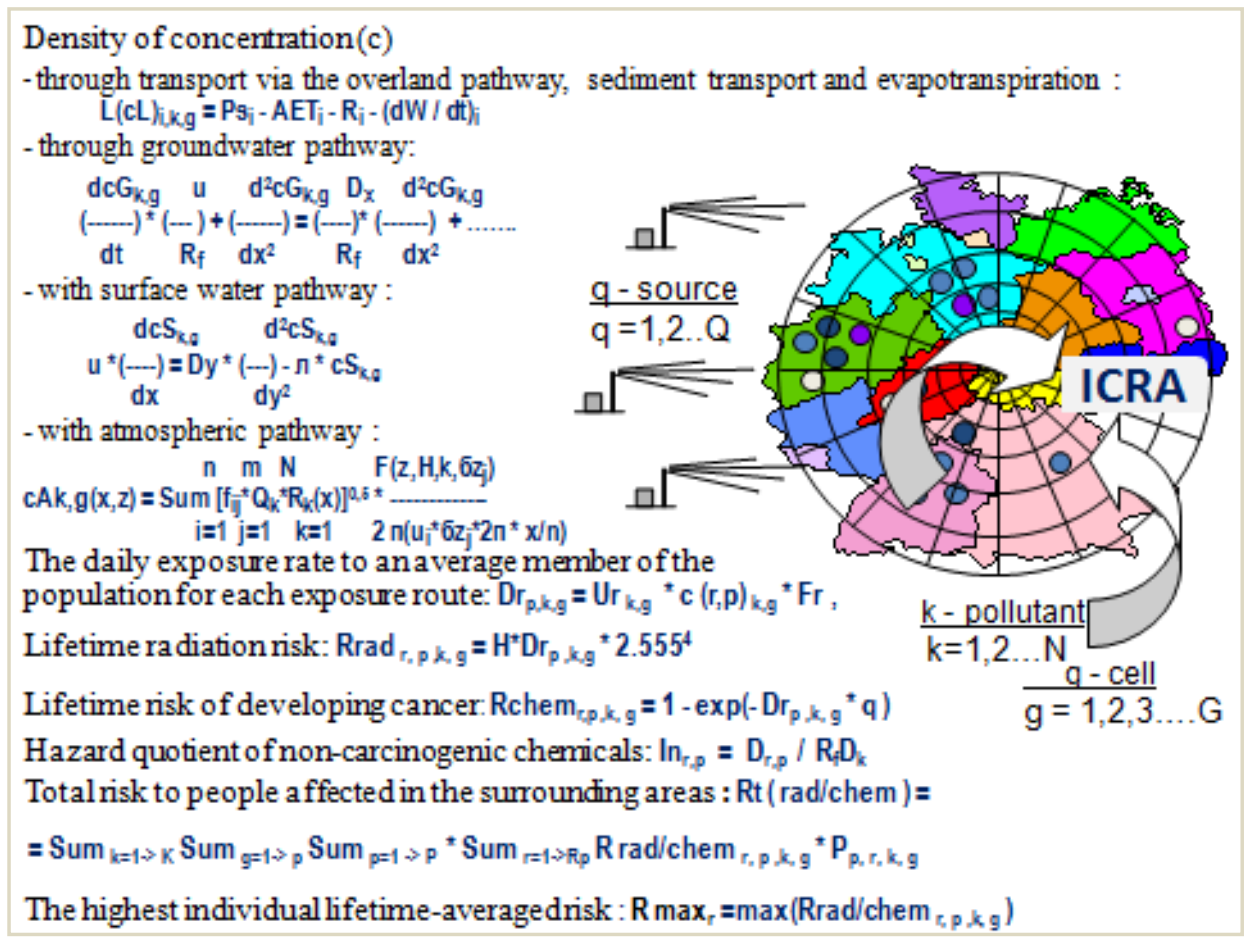

Figure 9. A general idea of the risk assessment algorithm within the ICRA method

\subsection{Engineering of the Cellular Structure of Decentralized Systems}

Idea a safety system with the distributed decentralized management, its structure and its basic components in a frame of C-SP'Kits was born and tested by the personal experience of the direct participation at two nuclear accidents within nuclear submarines in 1955-1961, and then in the process of protection and rescue of the own family within Chernobyl' nuclear accident 1986-1988 [7]. Later, at 1993-2002 the concept of the Decentralized Systems and C-SP'Kits has acquired the final forms. This happened after development of the MEPAS Russian version and its successful test in a few Eastern European areas overfull by potentially hazardous nuclear and chemical biological facilities. $[9,18,5]$

Eventually, precisely the cellular structure of distributed managing systems has been selected. This is because using only managing systems with the cellular structure can be provided real protection, safety and survival to individuals and their families who are distributed over populated areas..

Every C-SP'Kit is considered as one of the self-contained cells and their aggregate represents the whole Decentralized Systems. Thus the original intention in searching an alternative to the existing Centralized Systems providing protection and safety for whole population has been converted into searching for practical realization of the worded the self-preservation imperative. Finally the C-SP'Kits providing self-preservation of each person were developed on the basis of this imperative (originally as "systems kits of individual protection" .[1-3, 5]

\subsection{Basics Concept of Mathematical Support of Algorithms for ICRA and the Basic Models of the C-SP'K}

The first and most important step in the practical realization of the ICRA methodology concept was made in the early 1990s. A graceful computer program named as the Multimedia Environmental Pollutant Assessment System MEPAS was created at the Battelle PNNL, WA. [22]

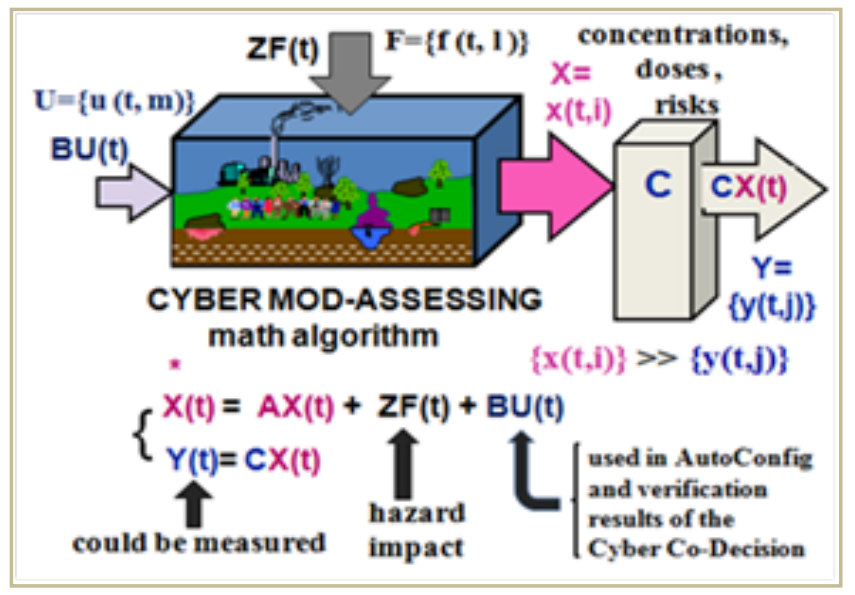

Figure10. The mathematical structural diagram for algorithm modeling and computation in the Cyber Mod- Assessing.

This software allows assessing risks to receptor individual from many sources of environmental hazards, namely, from contaminated air, soil, and water pathways, as well as linked combinations of these contaminated pathways. MEPAS is a physics-based approach, coupling contaminant release and migration and fate for environmental media with 
exposure routes and risk/health consequences for radiological and non-radiological carcinogens and non-carcinogens [22, 23].

Purpose and content of computational processes occurring in the numerous of Risk Observers and Computer Advisers belonged to any individual preservation kit are illustrated through a mathematical structural diagram Figure 10. It should be noted, the mathematical algorithm what is presented in this Figure does not claim any resemblance or similarity with the "black box" algorithm (see the upper sub-block in Figure 11 below). The math being interpretation of the ICRA methodology was proposed for engineering of software for personal preservation kits, i.e. the C-SP'Kits. The vector differential equation or so called "equation of state" represents the mathematical algorithm or mathematical model of a target process or a phenomenon.

The meaning of mathematical notations used in the mathematical chart on the Figure 10 are: $X(t)=\{x(t, i)\}$ and $\mathrm{X}^{\prime}(\mathrm{t})=\left\{\mathrm{X}^{\prime}(\mathrm{t}, \mathrm{i})\right\}$ - transposed vectors of state for a process/ phenomenon in question with dimension " $n$ " and its first derivative $\mathrm{xi}$ as "the state variable"; A,Z,B - matrix of coefficients of the dimension $n * n, n * 1$, and $n * m$ respectively; $\mathrm{U}=\{\mathrm{u}(\mathrm{t}, \mathrm{m})\}$ and $\mathrm{F}=\{\mathrm{f}(\mathrm{t}, \mathrm{l})\}$-transposed vectors of inputs with the dimension $\mathrm{m}=<\mathrm{n}$ and $\mathrm{l}<>\mathrm{n}$. Measurable outputs in such case might define the function of "state vectors" as $\mathrm{Y}(\mathrm{t})=$ $\mathrm{CX}(\mathrm{t}), \mathrm{Y}(\mathrm{t})=\{\mathrm{yj}(\mathrm{t})\}$ is transposed vector of output signals with dimensionality $\mathrm{v}=<\mathrm{n} ; \mathrm{C}$ - matrix of coefficients with the dimension $\mathrm{v} * \mathrm{n}$.

\section{Results. Cybernated Self-Preservation'Kit: Design and Developing}

A fundamentally important note in advance: the concept, content and design of the bio-technical composition submitted below have nothing in common with an attempt realizing the ideas of so-called "artificial intelligence"

The triadic bio-cybernetic composition of mutually supportive components is represented by three ones. The first is the component of the biological self-preservation. This is the human brain of an ordinary man who uses the C-SP'K. It generates the first set of decisions on the self-preservation for the human survival. The second one is a cybernetic device for computational simulation and calculations. This component is named the Cyber Mod-Assessing. It contains computer programs for assessing values and simulating dissemination of dangers and risks. The Cyber Mod-Assessing also elaborates trajectories for avoiding dangers by the man who uses of the C-SP' $\mathrm{K}$ in the case of evacuation. The third component is the Cyber Co-Decision. It's the second cybernetic device of the C-SP' $\mathrm{K}$, which is intended for performing of concluding operations. So, the Cyber Co-Decision makes a comparative analysis of the results obtained earlier at the first two components and participates in the subsequent selection of optimal decisions for survival in emergencies together with the first component.[3]

\subsection{Functional structural scheme of composition the Cybernated Self-Preservation 'Kit.[3,6]}

The C-SP'K block scheme may be represented by three sub-blocks: the upper is biological self-preservation, the lowest is a cybernated analog / model of biological self-preservation, and the average sub-block is a contingent image of a hazard area, in assessing of which the C-SP'K's user is interested.

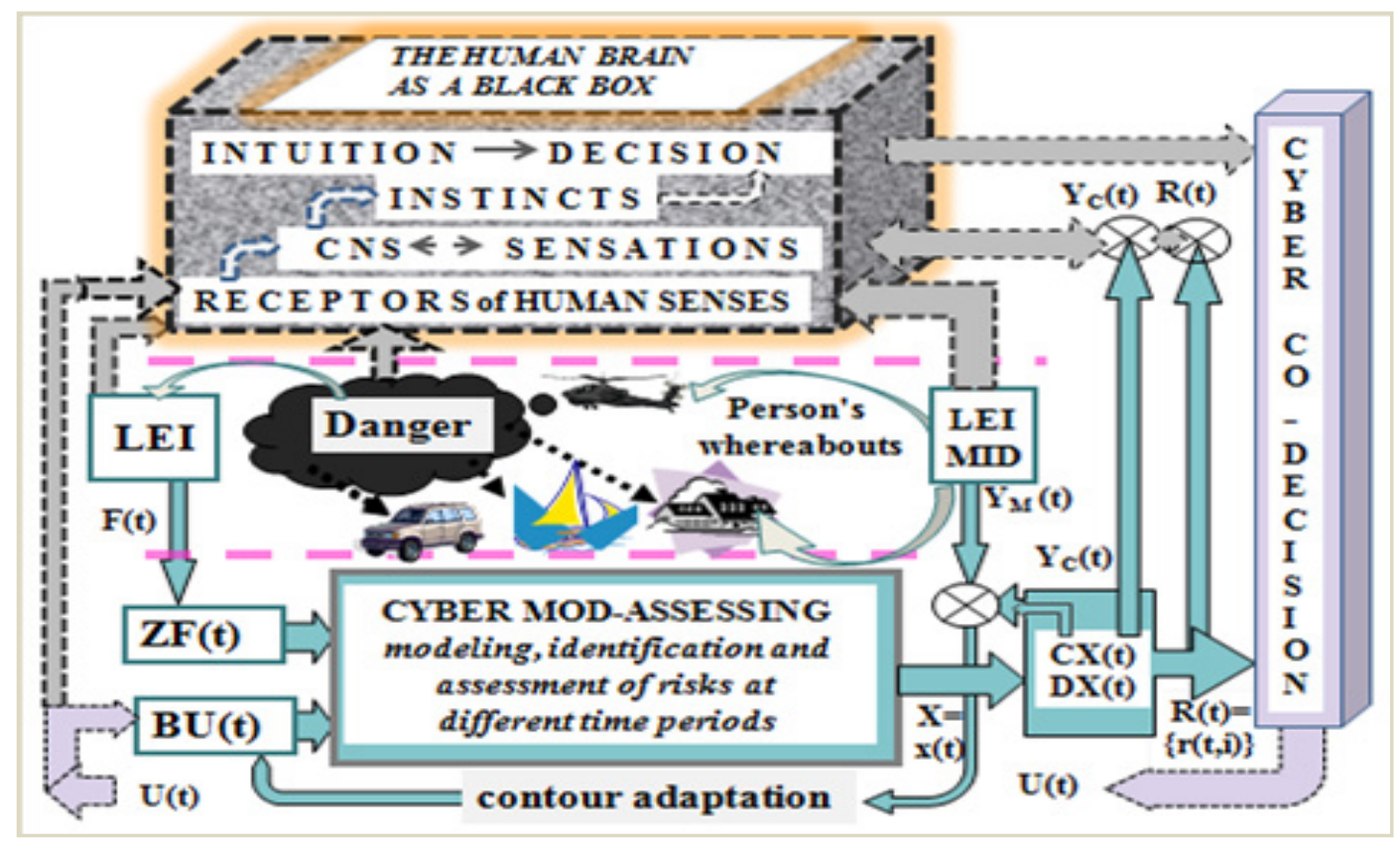

Figure 11. Functional structural scheme Cybernated Self-Preservation' Kit 
The uppermost part of the figure showing the basic sub-block of the C-SP'K representing a sequence of formation decisions by the human brain on self-preservation in very general outline (see the top sub-block conditionally represents the function of the human brain in the form of black box, moving through the levels from the bottom up. Information about external irritants acts on RECEPTORS of the human senses: visual, auditory, olfactory, tactile (tactile), taste, and kinesthetic. The RECEPTORS in turn materialize a form of sensory perception into the subjective submitted subjects and situations. The dashed arrow in Figure 11 . showing the conditional path for obtaining of desirable informative communications of the RECEPTORS with the sources of DANGER (it's unreal as the sensitivity of human biological receptors is insufficient for a direct perception of the any global / regional danger of modern noosphere). Dangers. The real perception of overwhelming majority today's threats through biological RECEPTORS is impossible. This is due to the absolute mismatch of ranges of human biological receptors, on the one hand, and of physicochemical parameters manifestation of the DANGERS in the modern post-industrial world, on the other. Actually the RECEPTORS can receive information on DANGERS but always just via technical intermediaries. In most cases it from the emergency information channels and measuring instruments type of LEI and MID, i.e., via the limited visual and auditory contacts with them (see arrows with solid lines). Such kind of inevitable technical information intermediation is significantly distorts the perception of nature subjects and phenomena by the human brain in their entirety. They can be perceived just in only certain range of qualities and properties that are presented by the governmental information channels and measuring instruments belonging to the man- user of the C-SP' $\mathrm{K}$.

- Signals taken by RECEPTORS from emergency information channels and measuring instruments LEI and MID are transmitting them in the central nervous system (CNS). The CNS analyzes and identifies the incoming information and then converts the signals into SENSATIONS.

- SENSATIONS, in accordance with the fundamental instinct of self-preservation and intuition stimulate the making of individual decisions on survival. These decisions are specific to each ordinary person using the C-SP' $\mathrm{K}$.

- The idea on the DECISION to survival, if there is no the C-SP' $\mathrm{K}$, is transmitted along the nerves to the appropriate organs of the body. The possibility of optimizing decisions is one of the most important features of C-SP'K. Variants of SUBJECTIVE DECISIONS that are induced by bio-complex receptors - sensations - intuition - fundamental instinct of survival in the presence of C-SP'K can and have to be compare with THEIR NUMERICAL ANALOGS, which offer computational blocks of C-SP'K (see the sub-block DECISION MAKING and of the computed vector of individual risk $\mathrm{R}(\mathrm{t})=$ $\{\mathrm{r}$ (r, i) \}, which converted to an index of a BALANCED DECISION U ( $t$ ) in Figure 11).

- Exactly thus is solved the most important task posed to the C-SP'K, i.e., to awaken and strengthen the inborn instinct of self-preservation in man when making decisions for his / her own rescue and survival. The SUBJECTIVE DECISIONS that are generated by THE RECEPTORS - SENSATIONS INTUITION - FUNDAMENTAL INSTINCT of SURVIVAL can be compared and matched with those which offered by the computing units of the C-SP'K. Ability to associate and compare SENSATIONS with the calculated parameters of dangers $\mathrm{YC}(\mathrm{t})$ and individual risk $\mathrm{R}(\mathrm{t})$ is one of the most important distinctive features of the C-SP'K (see the comparison of SENSATIONS with indices of dangers $\mathrm{YC}(\mathrm{t})$ and individual risk $\mathrm{R}(\mathrm{t})$ on the Figure 9).Thus using the C-SP' $\mathrm{K}$ is awakening a sense of self-confidence in the ability of each and every man who use the C-SP' $K$ to withstand any hazards and phobias. As a result using the C-SP'K allow to get rid from total paternalism and bureaucracy while exist a need to respond on the emergency situations. So any average man who uses the C-SP' $\mathrm{K}$ can avoid at last the special dangers generated by negative features of the Administrative Response to Emergency Situations (AR-ES). These are an irresistible inertia of the response to emergency calls, explained by the use of political and economic criteria when making decisions as well as orientation toward protection of the population in general rather than of every particular person.

A remark. As known exactly by the above listed negative features of the AR-ES are explained the numerous PHOBIAS. We mean the phobias, which are the main cause of most serious illnesses and deaths of people who found themselves in risk zones from the consequences of severe industrial catastrophes as well as natural disasters, military and terrorist acts.

Average sub-block is a contingent image of a hazard area, which interested of the C-SP'K user.

- The LEI and MID are means for receiving outside information. Entire information about all kinds and types of menaces / dangers / hazards within 100 miles from the current location or Residence of the Individual has to be available. It has to be done on an equal basis with authorities of any level without concealment and at exactly the same time. A notification about emergency events and their quantitative characteristics has to follow along the alarming channels of the AR-ES and HS-M without of retardation and censorship to the C-SP'K users.

The LEI and MID are abbreviations of "Links with External Information Resources" and "Measuring Instruments of Dangers".

The lowest sub-block- it is the cybernetic device for computational simulation and calculations, designed to solve 
the same problem as the brain that is, are part of the of the complex information technology of the C-SP'K. This sub-block has the following components :

- The Cyber Mod-Assessing, , that is computation unit includes computer programs for assessing values and simulating dissemination of dangers / hazards / risks. They allow not only estimating the magnitude and dynamics of individual risk variation but and suggesting trajectories for avoiding dangers / hazards by the man-user in the case of evacuation. The purpose and content of computational processes are illustrated through a mathematical structural diagram below. The vector differential equation or so called "equation of state" represents the mathematical algorithm or mathematical model of a target process or a phenomenon. It should be noted once again, the mathematical algorithm what is presented in Figure 11 does not claim any resemblance or similarity with the "black box" algorithm (see the upper sub-block in Figure 11 above). The successful operation of the Cybernated Self-Preservation' Kit all composition has nothing to do and does not envisage any knowledge of the biological algorithm, i.e. of that system of rules or regulations which is used by the human brain while information processing.

- LEI, that is the Links with External Information Resources realizing the personal communication of the C-SP'K user with media channels. The LEI allow obtain information about external dangers, threats and also meteorological information through the alarm channels of the AR-ES and HS-M.

The C-SP'K user should be know that the information on concentrations and potentials of pollutants, as well as about doses and risks obtained from the AR-ES and HS-M alarm service, i.e., over the LEI, most often is unauthentic. That is, and decisions, if they will prepare on the basis of such information, will be mismatched as a rule. This is why the information received through the LEI is processed in a special way, with the program of reverse recounting in the computing block $\mathbf{Z}^{*} \mathbf{F}(\mathbf{t})$, and only then goes to the main computer programs of the C-SP'K.

- MID , that is the Measuring Instruments of Dangers for estimation of a hazard level for the C-SP'K user at his/ her location;

The upright sub-block the Cyber Co-Decision is intended for performing concluding operation for comparative analysis the results obtained earlier at the first two ones C-SP' $K$ components and subsequent selection of, by the C-SP'K's user, optimal decisions for survival in emergencies.

- The Cyber Co-Decision The Cyber Co-Decision block is equipped with computers and appropriate software which provides performance of analysis and developing a data base for making decisions within challenges that formed by the C-SP user himself. The user can doing these through conducting of a concluding process a comparative analysis and an emulative process where the results obtained from two other components i.e., from the human brain of the C-SP'K user and from the block of Cyber Mod-Assessing, will be compared. Such is the mechanism of choosing optimal decisions, which can hereinafter provides of minimizing disease severity and excluding phobias. Thus is realized a maximizing of survival of a real individual - user of the C-SP and his/her family and also neighbors who are involved into the natural and technogenic emergencies including those caused by terrorist or military actions.

\subsection{Resources and means which are needful to implement the decisions taken on the basis C-SP' $K$ to be rescued and survive to an ordinary man and his/her family}

The implementation and fulfillment of the C-SP' $\mathrm{K}$ decisions assumes the existence and availability as minimum of the following items [6]:

Protective materials, facilities, resources and means for individual's protection;

Instruments and apparatus for monitoring dose burden and health status of an individual man;

Means for individual informative visualizing.

In turn, the list of the protective materials, facilities, resources and means for individual's protection includes:

Personal protective equipment, e.g., protective clothing, helmets, etc.; Protective materials helping to transform personal property and personal transport into a refuge from the impending danger.

Further, the list of the instruments and apparatus for monitoring dose burden and health status of an individual man includes:

Measuring instruments for personal use when measuring the level of various dangers and threats in the immediate vicinity of the individual have to fulfill; Personal measuring instruments for the measurement of various menaces in the immediate vicinity of the individual.

At last, the list of means individual informative visualizing includes:

Monitors, screens and indicators for visualizing levels of potentials of contaminations, doses and risks and their threats ( e.g., monitor Risk Distribution), as well as changing geographic coordinates ( e.g., monitor GPS) or epicenters accidents / natural calamities and also timing of moving the front waves of various hazards and threats.

Construction materials, air and water filters, also materials and equipment for decontamination, detoxification, disinfection and other aims - all what is necessary and allows converting a personal real property and personal transport into refuges.

Availability and accessibility of such materials and equipment supplied by individual request must be provided in advance by the local administration within the preparation 
of the given administrative territory for emergencies.

It has to be mentioning also water supplies, food, medicines, medical equipment, as well as clothes and stuff, which is necessary for life in the case of evacuation [24].

\section{Discussion. Potential Expensiveness and the Relative Difficulty to Use the C-SP'Kit for a Poorly Educated Person.}

The author's judgment about the ways of solution of the problem that has the immense importance for majority of us is formulated and set out above. In this section will be discussed the some difficulties and doubts into correctness of solutions in the field of methodology, design, technology and the rules of using the C-SP'Kit. Constructive views, advices and any other forms of participation of readers will be high appreciated and accepted with thanks as that will facilitate and promote the work in the given field of applied sciences.

\subsection{1st Issue for the Discussion: Where and How to Find the Data Sources of Information for LEI}

LEI is the weakest point in the design of the C-SP'Kits (see location of LEI in the Figures 11-12). LEI as a "newborn's umbilical cord" connects the C-SP'Kits with bureaucratic administrations who manage the actions of rescue in emergency situations.

Three irresistible "clannish blemishes" of the bureaucratic leadership were already enumerated before. That is a concealing of real information from the population (a fear to provoke a panic). The next is always inertia in decision-making and implementation process (because of bureaucratic doubts about the authenticity of information). And at last this is the selection of the wrong criteria in the orientation of priorities for activity in emergency situations (more increased attention to a source of a disaster, but not to the potential victims with the obligation to take into account the characteristics of the each real individual).[7,

All of the above "ancestral defects" bureaucratic leadership of emergency actions are the cause of the unacceptability of the data received by the C-SP'Kits user from the LEI.

The solution to this problem should probably seek to create a network of sources of information for data about the natural and man-made disasters and terrorist and military actions, which would be independent from the information systems of modern central and municipal emergency centers. The GPS 'network and the Internet also may be considered as examples of this type networks.

\subsection{2nd Issue for the Discussion: An Optimal Way for Designing of Assembling the C-SP'Kits.}

There is a difficulty in the right option of the configurations and subsequent technology for the kit C-SP assembling. This option can meet two contradictory requirements:

1. provide the full implementation of tasks for decisions optimization to rescue and survival of an ordinary man with requirement of minimum of information - technical equipment on the one hand;

2. sizes of a C-SP's kit or any individual components of the C-SP's kit, if they are intended to carry out specific independent tasks without help from others, should be such that every could be placed in the casing with spatial dimensions similar to sizes of a cell-phone.

There are at least two variants for the satisfaction of the first requirement, and, unfortunately, only with a partial performing of the second one.

The first variant is to conserve and use every time the kit C-SP as a whole. But this supposes a significant development of functions and precise designing the Cyber Co-Decision component. The functional block diagram of the variant is illustrated in Figure 12.

Second variant is a partition of the C-SP' kit on six separate kits, each of which has to be quite suitable to carry out the particular independent tasks without the other ones. The functional block diagram of such variant is shown in Figure 13. This design version of a C-SP' kit was already partly described in the $[3,6,10]$. However, the discussion of the both variants of such designs needs to be continued as the alternative ones.

\subsubsection{The Whole C-SP' Kit with a Significant Development of Functions the Cyber Co-Decision Component}

We have to turn to the upright sub-block that on the Figure11 above. There it possible to see the image of Cyber Co-Decision component. This is very important and complex part of the C-SP'K which can be named by the key part of the whole kit. It is equipped with computers and pertinent software to provide performance of analysis and making decisions for individual survival in emergencies.

The whole C-SP' kit with a significant development of functions the Cyber Co-Decision block.

So, the first variant of the designing of assembling the kit $\mathrm{C}$-SP as a whole and with the significant development of functions the Cyber Co-Decision's component will be considered below. The functional block diagram of the variant is illustrated in Figure 12

The list of the basic cybernated sub-component of the Cyber Co-Decision includes [3]:

CASP - Computer Adviser for Self - Prevention designed to select protective materials for transforming personal property into a refuge from the impending danger with using of Manual Screening to select Personal Realty Protective Materials ( the list of materials submitted in the item 4.2. above);

CART - Computer Adviser for Realty Transformable into a Refuge was designed to select the Personal Protective Equipment (PPE) and Personal Measuring Instruments (PMI) through the Manual Screening of PPE and PMI ; 


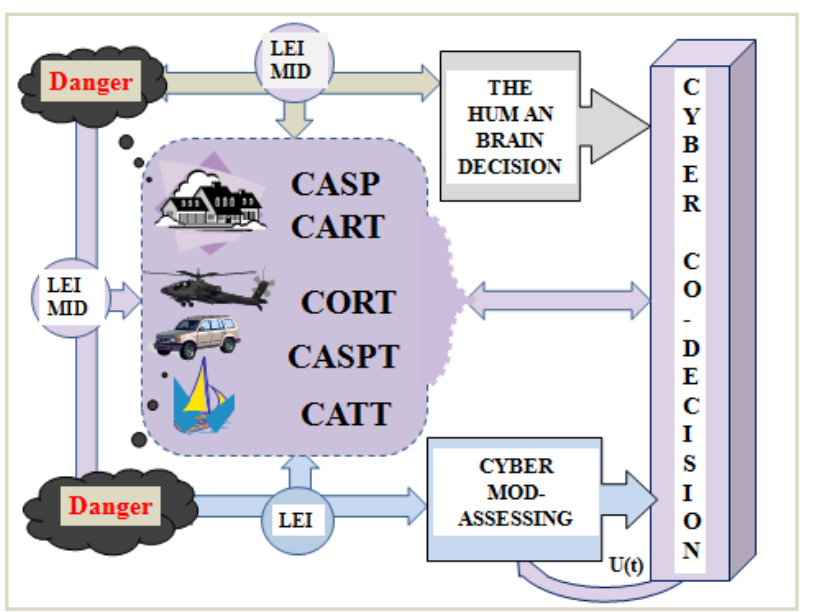

Figure 12. Functional interrelation and interdependence of the basic cybernated sub-components of the Cyber Co-Decision .

CORT - Computer Observer for Risk identification in area of locating personal Transport was designed to calculate Distribution of Risks for Individual from all menaces / hazards / dangers around the personal transport, i.e., a car, boat or airplane and at other types of private transport, where the individual is located at the present time (the area of risk assessments - a circle with a radius up to 80 miles);

CASPT - Computer Adviser for Self- Prevention on Transport was designed for selecting protective materials helping to transform personal transport into a refuge from the impending danger through Manual Screening that help to choose personal Transport Protective Materials ( the list of the part of such materials is submitted in the item 4.2. above);

CATT - Computer Adviser for Transport Transformable into a Refuge was designed for selecting Personal Protective Equipment (PPE) and Personal Measuring Instruments (PMI) through Manual Screening which help to transform private transport into a refuge ( the list of the part of such materials is submitted in the item 4.2. above).

\subsubsection{Six Separate Sub-Kits that Together Represent the} Cyber Self-Preservation' Kit as the Whole and Thence an Each Of Them Is Designed To Fulfill a Separate Task

On the discussion here is submitted the variant of a design while the six separate sub-kits of the C-SP'K are used for forming an action plan for decisions optimization to the rescue and survival of an individual in the different situations.

Such variant of configuration the C-SP'K is shown on Figure 13.

Description of the C-SP' Kit above in Chapter 4, see also Figure 11, was limited by scope of a survey of the functional diagram for the entire Kit. In really there are six main tasks as a minimum which can be performed with six separate sub-kits. The partition of the whole C-SP Kit on the six separate sub-kits could more easily fulfill the second requirement stated above in the paragraph 5.2. ( more easyly to fix a sub-kit in a casing with sizes of a cell-phone).

Such variant of configuration the Cyber Co-Decision component is shown on the Figure 13.

In addition to the above list of functional units in this list is SARO.

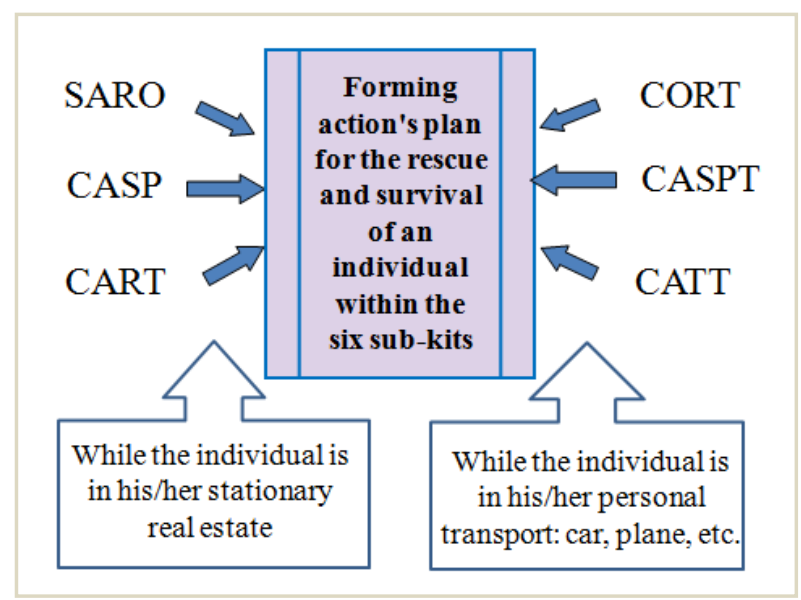

Figure 13. Functional block-diagram of the agreement within the six sub-kits while forming action's plan for the rescue and survival of an individual.

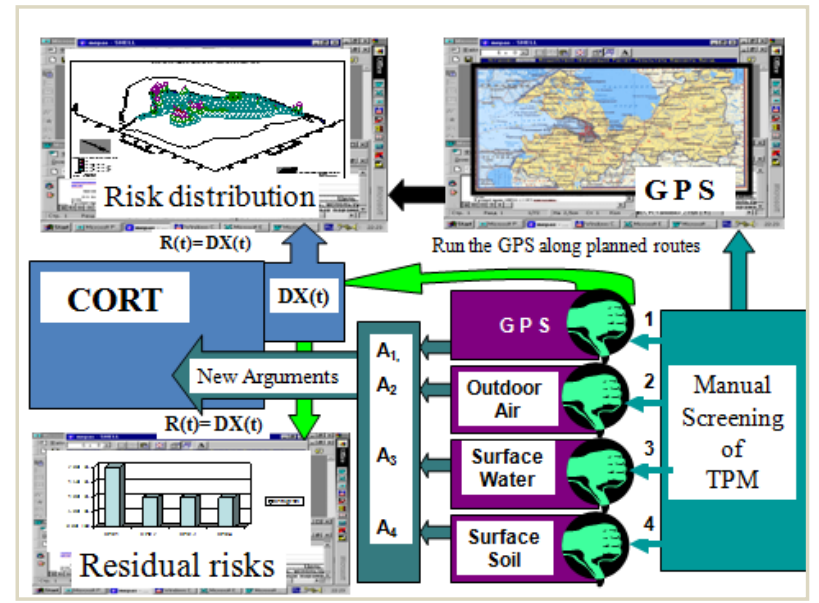

Figure 14. Mathematical block-diagram of the sub-kit CASPT that uses for selecting personal transport protective materials (TPM) through Manual Screening.[3,6]

SARO - Self-Adapting Risk Observer was designed to calculate Distribution of Risks for Individual from all menaces / hazards / dangers around the point where the individual is located at the present time (the area of risk assessments - a circle with a radius up to 80 miles);

A sample of math structure typical in some measure for a sub-kit is shown on Figure 14. [3 ]

\subsection{3th Issue for the Discussion: A Complexity in Using and a Relative Expensiveness of the C-SP'Kits}

As was written the specialized protective and safety measures for person preservation would be actualized by the individual preservation with the C-SP'Kits. In turn, the C-SP'Kits will constitute a matrix structure of the 
Decentralized Systems. This is why exactly the C-SP'Kits have to be distributed among the ordinary people.

Meanwhile, in reality, the virtually is not easy embody such task for two reasons.

Firstly, because of their complexity, as imply from the person of certain knowledge and experience to work with computer models.

Secondly, because of the C-SP'Kits cost may be high, at least in the initial period for these Kits implementation. These concerns should be discussed and a solution should be found.

\section{Conclusions}

Creation and implementation of the Cybernated Self-Preservation Kits is by the main practical result that can filling the existing nowadays very dangerous gap between the innate but the weakened biological ability of man survive on the one hand, and the expensive but impotent centralized bureaucratic structures of emergency response, which also unable to perform its function of providing protection and safety of a real individual from the dangers of the post-industrial environment of the 21 st century, on the other. The triadic bio-cybernetic composition named "Cybernated Self-Preservation' Kit" is filling out this gap. As a starting point for design, developing and implementing the strategic objectives of rescue and survival in the framework of the C-SP has to be posed and solved at least three tactical tasks on rescue and survival of each and every man with respect to any industrial accident caused by human errors, natural disasters or terrorist actions, for beginning.

The first task is to provide adversarial of mind and Cybernated devices while designing and then for using of the C-SP'Kit in further. It's necessary to wake and then strengthen of sureness in usefulness of the biological instinct of self-preservation when making decisions. Awaken a sense of self-confidence in the ability to withstand any hazards and phobias in every person that uses the C-SP' Kit ("El sueo de la razn produce monstrous", i.e., "Sleep of the mind produces monsters").

The second task for using the C-SP'Kit is to ensure the survival of any individual in the first three days of the start of distress, and including - developing the action plan to transform his / her home in the short-term refuge. Thus, a fatal gap in effectiveness of currently existing bureaucratic systems and services while they unable help every single person response to emergency events in the first hours and days will be filled out at last by real rescue actions on the base of the C-SP'Kit.

The third task is to provide of each individual a clear program of action in case of evacuation in the future, that is, in the fourth and subsequent days of an emergency, with using only the C-SP'Kit, i.e., without support of the existing bureaucratic systems and services to respond to extraordinary events.

The fourth task is to ensure through the C-SP'Kit the readiness of each individual to live in a time of global catastrophic event when the task of rescue and survival beyond the possibility of bureaucratic systems and to respond to extraordinary events transform a man's home in the long-term refuge in the case of global dangers and again just on the base of the C-SP'Kit advices.

So, who can get a place in the Noah's Ark of the 21 st Century? The answer is only that person who has in his/her ownership a Cybernated Self-Preservation' Kit and knows how to use the Cybernated Self-Preservation Kit.

\section{REFERENCES}

[1] The problems associated with the death of modern civilization. Online available fromhttp://www.lib.ua-ru.net/diss/cont/373044.html and http://www.twirpx.com/file/235963/

[2] The story on the Great Flood and Noah's Ark.Online available from http://ru.wikipedia.org/ andhttp://nawserial.ru /gdefon/oboi/download/324936-oboi-dlya-rabocheho-stola.

[3] Cybernated Self- Preservation. Contemporary Paradigm and Technology of Survival Concept, Design Developing,Implementing-Copyright (C) 2012 TXu $1-802-844$

[4] UNISDR. Online available from http://www.preventionweb. net/files/31737_20130312disaster20002012copy.pdf

[5] James G. Droppo, Dennis Bley, and Vitaly Eremenko (2003). Risk Methodologies for Technological Legacies // Science Series, Earth and Environmental Science-Vol.18, Dordrecht-Boston-London, 2003, 366 pp.Online available fromhttp://isbndb.com/d/book/risk_methodologies_for_techn ological_legacies_a01.html

[6] Vitaly A. Eremenko : Information Technology in Contemporary Paradigm of Survival / "Future Information Technology and Management Science \& Engineering, Hong Kong 2012". Lecture Notes in Information Technology and Advances in Artificial Intelligence pp.454-461, 2012. Online available from

http://www.ier-institute.org/2070-1918/lnit14/ v14/454.pdf'

[7] V. A. Eremenko and J. G. Droppo, Jr.: A Personal Experience Reducing Radiation Exposures: Protecting Family in Kiev During the First Two Weeks after Chernobyl / Operational Radiation Safety. Health Physic.Vol.91, No.2 (2006). Online available from

http://www.ncbi.nlm.nih.gov/pubmed/16823271

[8] V. Eremenko, An alternative to the existing dominant of risk analysis \& management in systems providing population safety, Proc. Of the SRA Annual Meeting, 2009 .Baltimore, MD, Dec.6-9 (2009). Online available fromhttp://birenheide.com/sra/2009AM/program/singlesessi on.php3? sessid $=\mathrm{P}$

[9] Vitaly Eremenko, James Droppo, Jr \& Dennis C. Bley. Human-centered risk assessment approaches for regions with a heavy burden of hazardous materials and meager financial resources / Content of 9th Annual Conference Risk Analysis: Facing the New Millennium Rotterdam - The Netherlands October $10-13,1999$. Online available 
fromhttp://www.riskworld.com/abstract/1999/SRAeur99/Pro gramSRAEU99.htm

[10] Vitaly A. Eremenko: Decentralization of Safety Management Could Protect Every Individual From Many Menaces and Hazards /Beyond Experience in Risk Analysis and Crisis Response. Atlantic Press, Paris, France (2011) pp146-152 and US Copyright (C2011 TXu 1-725-980.Onlinea vailable

fromhttp://hexiaini235.blog.ccidnet.com/home.php?mod=sp ace \&uid $=55406 \&$ do $=$ blog \&id $=20599159$

http://ndrisk.5d6d.net/archiver/tid-1918.html

[11] Cybernated Self-Preservation (C-SP), that is a triadic bio-cybernetic composition with the mutually supportive components, that enabling maximize the survival of ordinary man among natural and man-made dangers the contemporary post-industrial world. Submitted as provisional application for patent, 2012.

[12] Biological self-preservation. Online available from http://en.wikipedia.org/wiki/Preservation

[13] The Self-Preservation Instinct.Online available from http://www.swami-krishnananda.org/patanjali/raja_59.html

[14] The meaning of the word Cybernated.Online available from http://www.scrabblefinder.com/word/cybernated/

[15] Examples of cybernetic thinking. Online available from http://en.academic.ru/dic.nsf/enwiki/3237\#Definition

[16] The sense organs in humans.Online available fromhttp://ru.wikipedia.org/wiki/\%D0\%A7\%D1\%83\%D0\% B2\%D1\%81\%D1\%82\%D0\%B2 \%D0\%BE\%D1\%80\%D0\% B3\%D0\%B0\%D0\%BD\%D1\%8B̈\#.D0.9E.D1.80.D0.B3.D0. B0.D0.BD.D1.8B .D1.87.D1.83.D0.B2.D1.81.D1.82.D0.B2 _.D1.83_.D1.87.D0.B5.D0.BB.D0.BE.D0.B2.D0.B5.D0.BA
.D0.B0

[17] Self-preservation, part of an animal's fundamental instinct which demands that the organism survive. Online available from http://en.wikipedia.org/wiki/Preservation

[18] V.A. Eremenko, Optimization of Administrative Decisions Using the Multilevel Risk Assessment Methods, Proc. of the International Seminar, Erevan , Armenia”, 2002

[19] Guidelines for integrated risk assessment and management in large industrial areas. Inter -Agency Program ofIAEA-UNEP-UNIDO-WHO. IAEA-TECDOC -994. 1998 (V. Eremenko amongst the Contributors).

[20] V.A. Eremenko, Risk analysis in optimizing administrative decisions while towing of decommissioned nuclear submarines, Proc. Of the AMEC PROJECT on Buoyancy of Decommissioned Stored Afloat Nuclear Powered Submarines, 2004.

[21] V.A. Eremenko, J.G. Droppo Jr., and J.V Linde, Using population risk assessment as a basis for administrative decisions related to storage of irradiated nuclear fuels, Proc. Of the 11th International Conference on Environmental Remediation and Radioactive Waste Management, Bruges, Belgium", 2007.

[22] Laniak GF, JG Droppo, G Whelan, An Overview of a Multimedia Benchmarking Analysis for Three Risk Assessment Models: RESRAD, MMSOILS, and MEPAS. Risk Analysis 17(2), 1997.

[23] J. G . Droppo and V.A. Eremenko, Main Data of Licensed Computer Code MEPAS 3.11 RV, Proc. Of the International Seminar, Erevan, Armenia, 2002.

[24] Emergency products .Online available from http://echo-sigm a.com/shop/compare 